\title{
In July 2019 the Portuguese Society of Myology was officially born: the first message from the founders
}

\author{
Paula Tavares (1), Carlos Fontes Ribeiro (2) \\ (1) Faculty of Sport Sciences and Physical Education; (2) Faculty of Medicine, University of \\ Coimbra, Portugal \\ This article is distributed under the terms of the Creative Commons Attribution Noncommercial License (CC BY-NC 4.0) which permits \\ any noncommercial use, distribution, and reproduction in any medium, provided the original author(s) and source are credited.
}

\begin{abstract}
The amazing behaviour and adaptation capacity of the skeletal muscle system call the attention of several scientists, including us. Thus, we have the pleasure to announce that it was born in the city of Coimbra, Portugal, the Portuguese Society of Myology (SPMyo), a society which the main aim is to spread skeletal muscle knowledge in the areas of muscle physiology, physiopathology and pharmacology in a multidisciplinary organization that reflects the different areas of the skeletal muscle study. The commitment of SPMyo is the progress of skeletal muscle awareness as well as its investigation, encouraging interdisciplinary, national and international collaboration. These goals will be achieved by organization of scientific meetings, formation courses, publications of books and other scientific and didactic materials. It is also a goal of the SPMyo to organize public events allowing general public to understand skeletal muscle system.
\end{abstract}

Key Words: Portuguese Society of Myology - SPMyo, Muscle physiology and pathology, Muscle knowledgement and spread

Eur J Transl Myol 29 (4): 281-282, 2019

It is with a great honour that we announce a new muscle society, the Portuguese Society of Myology - SPMyo. The skeletal muscle is an exceptional organ that deeply engages those who study it due to its adaptability to several life circumstances as well as its cross-talks with other parts of the human body. Over the last two decades, there was an amazing increase in skeletal muscle research. Looking the year of 1990 we found, in the broad range of "skeletal muscle", 2318 full papers. In December of 1999 the number of full papers increased to 39425. If we look at the number of the full papers over the time until June 30th 2019, we found, just in PubMed, the amazing number of 248812 published papers. This number of publications, over the last years, show the increasing interest in this topic, wich reflects the recognition and importance of skeletal muscle. Skeletal muscle is indeed much more than a contractile system. It is not easy to summary the historical evolution of the human organ of motion. However, some key points on skeletal muscle research need to be highlighted.

Since the time of Leonardo da Vinci and Andreas Versalius in the XVI century, human muscles created a enchantment from art and science, sometimes in an indistinguishable way. However, the first report of muscle physiology and biochemistry seams to begin with Kühne in $1864 .^{1}$ This scientist isolated a viscous protein from muscle who his called "myosin", becoming one of the most important proteins in muscle contraction. Nevertheless, some authors considered that the first concepts (such as muscle fibers structure, and the muscle brain connection) was introduced by Leenwenhock and Croone, between 1675- 1680, with microscope observations of cross-sections of muscle fibers. In their theory was almost described the complete structure and function of skeletal muscle. ${ }^{1}$ Those theories needed, however, to be proved, and in the following years the study did not stop. In 1922 two scientists shared the Nobel Prize in Physiology or Medicine. Archibald V. Hill "for his discovery relating to the production of heat in the muscle", and Otto Meyerhof "for his discovery of the fixed relationship between the consumption of oxygen and the metabolism of lactic acid in the muscle". ${ }^{1}$ In 1957 AF Huxley described the muscle structure and the theory of contraction, postulating the cross-bridge cycle and the structure of the sarcomere ${ }^{2}$ Two years later (1959), after the first theory of Huxley, another scientist, Weber, described the role of calcium on its connection to myosin..$^{3,4}$ However, only in 1969 , the mechanism of muscle contraction through cross-bridges was described in details by HE Huxley. 5,6 The bigger protein of myofribrils, and also of the human body, was discovered in 1979 by Wang, et al., ${ }^{7}$ making another revolution on 
the elastic properties of the muscle fiber as well as of the stability of sarcomeres structure: this protein is titin. The regeneration of the skeletal muscle, a major research topic, is based on myogenic stem cells, most important being satellite cells. It seems that the first report of the existence of satellite cells is from 1865. In this date scientists observed some structures that they named "muscle corpuscles", but only around 100 years later in 1961, Alexandro Mauro and the Nobel laureate Sir Bernard Katz characterized those structures as being myogenic stem cells, namely, the satellite cells. ${ }^{8,9}$ This discovery is the scientific basis for muscle diseases treatment with cell therapy. Another landmark of skeletal muscle research was the fact that at the end of the XX century the skeletal muscle begin to be considered an endocrine organ able to produce and release more than 600 myokines acting over almost all organs of human body. ${ }^{10}$ These amazing discoveries bring more attention to skeletal muscle and much more key points that need research. The amazing behaviour and adaptation capacity of the skeletal muscle system call the attention of several scientists, including us. Thus, we have the pleasure to announce that it was born in the city of Coimbra, Portugal, a society which the main aim is to spread skeletal muscle knowledge - the Portuguese Society of Myology (SPMyo). The mission of SPMyo is to develop formation and spread knowledge in the areas of muscle physiology, physiopathology and pharmacology in a multidisciplinary organization that reflects the different areas of the skeletal muscle study. The commitment of SPMyo is the progress of skeletal muscle awareness as well as its investigation, encouraging national and international interdisciplinary collaboration. These goals will be achieved by organization of scientific meetings, and courses, and publications of scientific and didactic materials. Since science must also be of public interest, it is also a goal of the SPMyo to organize public events allowing general public to understand such fascinating system as it is skeletal muscle. The international cooperation and network (through the affiliation to the European and World Societies), as well as the promotion of young scientists in the myology area is on our action programme. The SPMyo was founded by the Professors Carlos Fontes Ribeiro and Paula Tavares that works at the University of Coimbra in skeletal muscle area since more than a decade. Regardless of SPMyo is Portuguese, it includes international members in the boards of the Society. Furthermore, the European Journal of Translation Myology (EJTM) will be the official journal of SPMyo. Thus we invited two editors of EJTM and one more international member. Ugo Carraro and Antonio Paoli from the University of Padova, Italy and Antonino Bianco from the University of Palermo, Italy were so kind to accepted our invitations.

We are proud and grateful that they agreed and that they will be part of our project. We are confident that many SPMyo members will contribute their results to EJTM.

\section{List of acronyms}

EJTM - European Journal Translational Myology

SPMyo - Portuguese Society of Myology

\section{Authors contributions}

Both authors played a substantial role in conception, drafting and final editing of the manuscript.

\section{Acknowledgments None.}

\section{Funding None}

\section{Conflict of Interest None.}

\section{Ethical Publication Statement}

We confirm that we have read the Journal's position on issues involved in ethical publication and affirm that this report is consistent with those guidelines.

\section{Corresponding Author}

Paula Tavares, Faculty of Sport Sciences and Physical Education, University of Coimbra, Portugal

Email: tavaresc.paula@gmail.com

E-mail of co-author

Carlos Fontes Ribeiro: fontes.ribeiro@gmail.com

\section{References}

1. Jin J-P, Bloch RJ, Huang X, Larsson L. Muscle contractility and cell motility. J Biomed Biotechnol 2012; 2012: 257812. doi: 10.1155/2012/257812.

2. Huxley AF Muscle structure and theories of contraction. Prog Biophys Biophys Chem 1957;7:255-318.

3. Weber A. On the role of calcium in the activity of adenosine 5-triphosphate hydrolysis by actomyosin. J Biol Chem 1959;234:2764-9.

4. Martonosi AN. Animal electricity, $\mathrm{Ca}_{2}{ }^{+}$and muscle contraction. A brief history of muscle research. Acta Biochimica Polonica 2000;47:493-516.

5. Huxley HE. The mechanism of muscular contraction. Science 1969;164: 1356-65.

6. Stull JT. Myosin Minireview Series. J Biol Chem 1996;271:15849.

7. Wang K, McClure J, Tu A. Titin: major myofibrillar components of striated muscle. Proc Natl Acad Sci U S A 1979;76:3698-702.

8. Mauro A. Satellite cell of skeletal muscle fibers. J Biophys Biochem Cytol 1961;9:493-5.

9. Katz B. How cells communicate. Sci Am 1961;205:209-20.

10. Whitham M, Febbraio MA. The ever-expanding myokinome: discovery challenges and therapeutic implications. Nat Rev Drug Discov 2016;15:71929. doi:10.1038/nrd.2016.153.

Submission: September 8, 2019

Acceptance: September 19, 2019 